\title{
Benign Nasal Cavity Neoplasm
}

National Cancer Institute

\section{Source}

National Cancer Institute. Benign Nasal Cavity Neoplasm. NCI Thesaurus. Code C4603.

A non-metastasizing neoplasm that arises from the nasal cavity. Representative examples include Schneiderian papilloma and salivary gland-type adenoma. 